\title{
Building trust and establishing legitimacy across scientific, water management and Indigenous cultures
}

\begin{abstract}
This paper positions legitimacy and trust within a post-colonial theoretical frame, challenging the fundamentals of Australia's water governance system as well as the presumptions of neutrality that underpin liberal water management principles of participation and inclusion. In a settler colonial society like Australia that until very recently excluded Indigenous people from all forms of water governance, there are very significant questions to be asked about legitimacy and trust in its water regulatory regimes, guiding policy directions and the fairness of the outcomes generated by its institutions. The paper describes attempts to build cross-cultural collaborative research and management partnerships in the environmental water sector and points to formal agreements as a mechanism through which parties, including governments, can negotiate rules governing legitimacy. As an expression of self-determination and recognition of the legitimacy of Indigenous modes of governance, agreements represent a marked improvement on the exclusionary legal, policy and knowledge-production processes that have shaped our current arrangements.
\end{abstract}

Keywords: participation, collaboration, deliberation, agreements, Indigenous peoples, Australia. 
Author's copy: Jackson, S. 2018. Building trust and establishing legitimacy across scientific, water management and Indigenous cultures, Australasian Journal of Water Resources.

\section{Introduction}

Over the past two decades there has been shift in water resource management away from the command and control paradigm towards decentralized processes of social decision-making and appropriate structures and procedures to support public participation in water governance (Mostert 2003; Tan, Bowmer and Baldwin 2012). A focus on the means of fostering shared visions, objectives and norms amongst communities of water users and other parties with a plurality of interests has accompanied this shift. It is a development that Schmidt (2014) refers to as water management's 'procedural turn' - an orientation that has 'favored the design of management institutions that allow for multiple viewpoints, multiple objectives and the capacity to reflexively respond to surprise and uncertainty' (1128). According to Schmidt, $(2014,1128)$ this procedural register is underpinned by the expectation that decision-making will occur through procedures 'that do not intrinsically favor the beliefs - the substantive goods - of any particular group'. Its promise is based on the presumption that 'fair procedures will produce fair outcomes' (Schmidt and Peppard 2014, 536).

Consistent with the promotion of inclusive and transparent processes as a key water management principle internationally, Australian water reform processes have drawn on the paradigm of public participation as a source of legitimacy and a means of effecting water policy change. Public participation sits alongside other institutional mechanisms, most notably the market-based and property rights instruments that are the centerpiece of national water policy. According to Tan, Bowmer and Mackenzie (2012), the National Water Initiative (NWI 2004) identifies three anticipated outcomes of public participation: improved certainty to build confidence in reform processes; transparency in decision-making; and sound information for all sectors at key decision points. In this pre-eminent policy document, community input is framed in instrumental terms: as a means to optimise outcomes in water planning processes and settle trade-offs. There is no explicit focus on political and ethical norms of trust (among stakeholders or in government) or legitimacy of decisions as goals or outcomes. 
Author's copy: Jackson, S. 2018. Building trust and establishing legitimacy across scientific, water management and Indigenous cultures, Australasian Journal of Water Resources.

In Australian national water policy consultation and information provision receive greater emphasis than active engagement, collaboration or even deliberation in social decision-making. Yet researchers consider the latter processes more conducive to building trust: they are higher up the 'ladder of participation', and therefore closer to decision-making power than the mere provision of information (Arnstein 1969). Ensuring the flow of information, though a necessary precondition or important first step, would appear to be insufficient in establishing legitimacy if, as is argued by Dryzek $(2001 ; 2005)$, deliberation is the basis of political legitimacy. As the means of obtaining the support of those affected by a decision (Dryzek 2001), deliberation requires more than mere information provision directed towards changing participant's attitudes and increasing their understanding. It needs some degree of negotiation and power sharing, as well as a willingness to make arguments in terms that others can accept (Dryzek 2005).

Such preconditions are especially hard to achieve when managing a vital, multivalent and finite substance like water. Water is of concern to many diverse groups of people with different positions, knowledge systems and normative frameworks and it is subject to 'social struggles along class, gender, ethnic, political, economic, and other lines of access and control' (Horangic et al. 2016, 1422; Schmidt and Peppard 2014; Jackson 2017a). The existence of partial and positioned knowledge demands the inclusion of representative discourses that reflect multiple perspectives on a water management issue (Schmidt 2014), and this in turn requires translation, mediation and negotiation (Ayre and Mackenzie 2013).

In the second half of this paper, I will point to research processes and other activities directed towards these ends with Indigenous communities in Australian environmental water management. Before doing so however, I will pursue an explicitly political question about legitimacy in the context of Australia's status as a settler colonial country (Wolfe 2006). Until recently, Australian society and its institutions denied the existence of Aboriginal customary law and management systems governing land and water. Here I use the term customary law in the same sense as Burchi (2005) who defines it as 'law and rules based on long-standing practice, not codified in written form'. Customary law pre-dates statutory water law. Agricultural development and other forms of water use involved encroachment of Aboriginal and Torres Strait Islander peoples' rights and 
Author's copy: Jackson, S. 2018. Building trust and establishing legitimacy across scientific, water management and Indigenous cultures, Australasian Journal of Water Resources.

interests in water, in addition to land, and it generated exclusive norms of water use that privileged the non-Indigenous population. Indigenous rights and interests were not reflected in national water policy until 2004, a full ten years after the Mabo High Court decision recognised native title (Jackson and Altman 2009; Taylor et al. 2017). When recognised in the NWI, the treatment was weak (see Marshall 2017; Tan and Jackson 2014). Historical acts of injustice and enduring inequities continue to shape the legal, political and institutional frameworks and procedures within which Indigenous peoples and others act and from which they seek fair, equitable and legitimate outcomes (Ivison 2017; Jackson 2017b). The ongoing effects of these post-colonial political relations, which trouble the theoretical appeals to neutrality inherent to the procedural turn (Schmidt 2014), produce tensions between programs and policies of Indigenous recognition and engagement that have wide currency and Indigenous perspectives on self-determination, jurisdiction and sovereignty (Hartwig et al. 2018; von der Porten and Loe 2013). The water policy, management and research sector needs to understand these tensions.

\section{Legitimacy in a settler society}

Backstrand (2006, 291) defines legitimacy as 'the quality of the particular social and political order: the normative belief held by actors that the particular rule, institution or order ought to be obeyed'. Bernstein states that legitimacy is the 'acceptance and justification of shared rule by a community' $(2005,142)$. In any plural society we can expect different groups to hold different views on the legitimacy of the governance system, but in a settler colonial society like Australia that dispossessed the Indigenous population, and de-stabilised its decision-making structures, there are very significant questions to be asked about legitimacy and trust. For example, in relation to the recent constitutional reform question Ivison asks:

'how can individuals and groups who suffer from historical injustice affirm their membership of a political community in such a way that political authority can be considered legitimate?' $(2017,2)$.

The unresolved social and political relationships between Indigenous Australians and other citizens continue to be matters of immense significance, as are the ways in which these 
Author's copy: Jackson, S. 2018. Building trust and establishing legitimacy across scientific, water management and Indigenous cultures, Australasian Journal of Water Resources.

relationships affect access to land and water and natural resources, their distribution, management and governance more generally. The situation facing water governance is similar in Canada where Indigenous nations have also not ceded sovereignty to the Canadian state (Schmidt 2014; Watson 2009). Despite differences in the legal status of First Nations between Australia and Canada, the latter is nonetheless an instructive case because analysts have called into question the legitimacy of that country's water governance system. Indigenous peoples hold unique legal standing in Canada by virtue of treaties and recognition of aboriginal title. Aboriginal rights are sui generis, in other words, they are political rights that 'flow out of indigenous nationhood and that are not bestowed by the Canadian state' (Turner 2008, 7). As studies from British Columbia (Simms et al. 2016; von de Porten and Loe 2013), Alberta and Ontario (Borrows 1997) demonstrate (Schmidt 2014), there is deep disagreement about jurisdiction, which is a very basis of legitimacy. In relation to water planning in Alberta, Schmidt $(2014,1137)$ says that

'the requirement for [First Nations] to articulate claims through procedures backstopped by the authority of the Canadian state does not fit with notions of fairness that respect their rights to alternate systems of resource management or self-governance’.

Indigenous legal scholar John Borrows (1997) argues that narrow jurisdictional boundaries marginalize Indigenous peoples from and within the procedures of environmental governance. First Nations like his Nawash people are

'caught between the peripheries of competing political jurisdictions. The relationships of federalism have been more attentive to national and provincial interests and thus constricted the political space within which Neyaashinigming operates. The community has little or no opportunity to influence environmental ideas, design, and decision making... These federalist structures organize, separate, and allocate water and rocks in a manner which promotes unequal distributions of political influence (418-419).

Due to its settler colonial history, Australia too has multiple, hierarchical and contested legal orders and spheres of political legitimacy. Political philosopher James Tully has explained that the defining 'ground of the relation' of settler colonialism is the 'appropriation of the land, resources and jurisdiction of indigenous peoples, not only for the sake of resettlement and exploitation ... 
Author's copy: Jackson, S. 2018. Building trust and establishing legitimacy across scientific, water management and Indigenous cultures, Australasian Journal of Water Resources.

but for the territorial foundation of the dominant society itself' $(2000,39)$. Australian Indigenous legal scholar Irene Watson, from the Tanganekald/Meintangk First Nations, raises the question of legitimacy when she describes the country's foundations as unlawful:

'Aboriginal worldviews struggle under an Australian colonialism that historically denied an Aboriginal presence and went on to build the Australian state's foundation. Although that foundation is based on the myth of terra nullius, Aboriginal peoples were and still are present, carrying laws and cultures that governed every space of Australia' (2009, 28).

In light of these thoughts on the links between justice, jurisdiction and legitimacy, it is important that we ask a question that as far as I know has not been asked directly in any Australian government-led water policy context: how is legitimacy to be achieved in a society that is divided by colonial relations of power? I acknowledge that in fully addressing this question we need to know what sources of legitimacy Indigenous peoples hold to be valid. For stimulating discussion however, and based on my experience in this area as well as the published and unpublished accounts of Indigenous peoples (see for example, Marshall 2017; Watson 2009), I offer two likely responses.

Indigenous communities within Australia have told many government processes and those interested in their forms of water governance that they look to their law and custom as a source of legitimacy for making decisions about water. The implication of this response is that the environmental water sector should be doing more to understand Indigenous peoples ways of making decisions, their views on political representation, conflict resolution, notions of fairness, methods of deliberation, stewardship and building shared objectives and inclusive strategies for solving problems.

John Borrows argues that in addition to changing both the people and ideas involved in settler institutions, we need a 'shift in the ground upon which decisions are made' (1997, 452; emphasis in original). To do so, would entail abandoning a requirement of water governance systems that 'those contesting existing practice conform to the procedures set out by those with political power as a condition of participation' (Schmidt 2014, 1138). Borrows identifies the need to strengthen environmental governance institutions through expansive notions of jurisdiction, saying that 
Author's copy: Jackson, S. 2018. Building trust and establishing legitimacy across scientific, water management and Indigenous cultures, Australasian Journal of Water Resources.

'enhancement of more inclusive structures, and the incorporation of a broader range of ideas, may assist democracies in making better environmental decisions ... our democracies would be strengthened as the principles and values of people from different constituencies were represented in public life. This will be accomplished as the intellectual traditions of First Nations are received in institutions partly of their making, using Indigenous legal principles as the very criteria upon which decisions can be judged and executed' (1997, 453).

To date, much of the current effort at the interface of Indigenous rights and environmental water, at least from a research perspective, is devoted to understanding and documenting 'Indigenous values', a task that the scientific or resource management community assumes entails studying the importance of waterbodies, waterways and other aquatic life (Jackson 2017a; Finn and Jackson 2014). Significantly, Indigenous researchers and/or organisations are increasingly leading this work or at least playing a significant part (see Taylor et al. 2017; Hemming and Rigney 2014; Jackson et al. 2015). For example, a major project on the determination of cultural flows in the MDB is due for publication at the time of writing. Although this is necessary empirical research, I argue it is not sufficient. Additionally we need to direct effort to understanding Indigenous modes of water governance and their articulation with those of the nation state, where governance is defined as the 'means, including processes and institutions, through which collective goals are chosen, decisions are made, and action is taken to achieve the chosen goals' (Cosens \& Chaffin 2016, 86). The ability of environmental water reference groups or multi-stakeholder advisory panels to acknowledge and respond to Indigenous claims and aspirations would be one interesting area for further research, for example (Cranney and Tan 2011).

There is considerable support for the work being done by Indigenous water alliances such as MLDRIN (Murray Lower Darling Rivers Indigenous Nations) and NBAN (Northern Basins Aboriginal Nations) from the Murray Darling Basin Authority (MDBA) (and its predecessor the Murray Darling Basin Commission) and other government water agencies. This support is a reflection of some awareness within the water sector of the legitimacy of Indigenous modes of governance. MDLRIN formed in 1999 after the Yorta Yorta lost their native title claim to land and waters in the Murray River region (Morgan et al. 2006). It was agreed an umbrella body was 
Author's copy: Jackson, S. 2018. Building trust and establishing legitimacy across scientific, water management and Indigenous cultures, Australasian Journal of Water Resources.

needed to represent traditional owners, to provide a platform to engage with government and articulate a stronger voice in policy and management responses to the severely degraded river system (Morgan et al. 2006). The model proposed included a board of delegates with representation from each traditional owner group. In 2011, an alliance of twenty-two indigenous nations from the northern basin, NBAN, formed to ensure that water governance processes embraced their perspectives. NBAN describes itself as an 'independent self-determining organization with a primary focus on cultural and natural resource management ${ }^{\text {' }}$

These alliances engage with state and federal government ministers and agencies, NGOs, and the agricultural sector, and they are regarded as valuable consultative bodies for policymakers and water managers (Weir and Ross 2017). Their formation has resulted in a strong partnership between Indigenous nations and the MDBA, formalized through a Memorandum of Understanding acknowledging the political authority asserted by the nations and various internal MDBA policies and plans (Morgan et al 2006). The MDBA has provided funding for the past fifteen years to enable employment of a coordinator for MLDRIN and NBAN, for group meetings, Indigenous facilitators to engage traditional owner groups at key wetland sites under a major environmental water program (the Living Murray), resources to map values and relationships of significance, and experimentation in the design and deployment of environmental health assessment. This and other work shows that community control stands out as an important aspect of Indigenous peoples' selfdetermination and is a most promising arena for understanding of the role of trust and legitimacy in environmental water management.

A second response to the question above relates to the origins of a national water framework forged through inter-governmental agreement. Because Indigenous representatives were not included in the negotiations that established the NWI (see Marshall 2017), Indigenous leaders and others have questioned the legitimacy of the rules that govern access to water and the framework for its management. The lack of engagement begs a question that paraphrases Drycek (2001): 'why should we attach legitimacy at all to a process that involved none of those whose concerns were actually being discussed?' Although Indigenous peoples had a substantial stake in these decisions,

\footnotetext{
${ }^{1}$ Who Are We? NBAN, http://nban.org.au/who-we-are/ (last visited Jan. 15, 2018).
} 
Author's copy: Jackson, S. 2018. Building trust and establishing legitimacy across scientific, water management and Indigenous cultures, Australasian Journal of Water Resources.

there was no dialogue with Indigenous representatives at the national level until well after the NWI when, in 2009, the NWC convened an Indigenous freshwater-planning forum (see Jackson et al. 2009). It was from this meeting that the first Indigenous advisory group, the First Peoples' Water Engagement Council (FPWEC), was established (Taylor et al. 2017). It appears that at some levels within the water sector this omission is acknowledged as a shortcoming that should not be repeated. Notably, the Report of the Productivity Commission Inquiry into implementation of the NWI (2017) recommends that Indigenous Peoples should be more directly involved in drafting the provisions relating to their rights and interests upon the renewal of NWI and recommends the establishment of an Indigenous Working Group. Whether the Council of Australian Governments accepts this recommendation remains to be seen.

Currently, there is no national Indigenous water advisory body or policy, an absence that Indigenous water policy commentators, Brad Moggridge and Anne Poelina (with Kat Taylor) refer to in a recent paper in this journal:

First Peoples hold the view that if we are to develop sustainable lives and livelihoods on country with our fellow Australians, it must be a true partnership which reflects the collective wisdom: values, ethics and the enshrined laws of both parties (Taylor 2017, 2).

Submissions from Indigenous organisations and academics to the NWC, and more recently the Productivity Commission, argued that the ad hoc and provisional quality of the support provided for Indigenous peoples further undermines trust in government processes. Taylor et al. (2017) offer an Aboriginal Water Strategy as a more promising means of ensuring consistency and commitment than the current approach:

Injections of financial investment create momentum, goodwill and build capacity. Then funding runs out, programmes end, and the knowledge gained is buried in archived government websites (e.g. the NWC's website). If programmes are not accompanied by legislative reform or other binding commitment, any progress made can be quickly lost (Taylor et al. 2017, 10). 
Author's copy: Jackson, S. 2018. Building trust and establishing legitimacy across scientific, water management and Indigenous cultures, Australasian Journal of Water Resources.

Australia has now been through a decade or so of experimentation in the area of Indigenous water management and there are many examples of positive and strengthening relationships. There are cases in Victoria showing that catchment management agencies (with responsibilities for environmental water management) are looking for practical ways of using held environmental water to achieve Indigenous objectives. Similarly, the Commonwealth Environmental Water Holder (CEWH) has declared a commitment to working with Aboriginal organisations and, to that end, has recently employed an Aboriginal engagement officer to strengthen ties between the office and the community. The efforts of the governments of Victoria and South Australia to build agency capacity and resource Indigenous communities is also a notable development. In Victoria's case, the State water strategy, Water for Victoria, includes a commitment to a $\$ 5$ million fund to support Aboriginal access to water for economic development, as well as a similar amount to an Aboriginal Water Program to incorporate Aboriginal values and expertise into water management. (https://www.water.vic.gov.au/water-for-victoria). The Victorian Government has committed to amending the legislated objectives of the Victorian Environmental Water Holder (VEWH), such that it is required to consider Aboriginal water-related environmental outcomes. A Victorian Aboriginal Commissioner was also appointed to the VEWH in 2017 (Productivity Commission 2017). Against this positive progress however sits the recent decision of NSW to disband the large Aboriginal water unit that, at its height, employed ten Aboriginal staff (Taylor et al. 2017).

In summary, numerous national assessments highlight progress in the degree of consultation towards understanding Indigenous objectives at the local scale, and in rates of Indigenous participation in water planning, but it must be noted that there has still been 'no material increase in water allocation for Indigenous-social, economic or cultural purposes' (NWC 2014). This recent era shows that addressing the colonial legacy will require a dedicated effort to confront the inherited structures that shape distributive outcomes. The NWI failed to provide mechanisms to address historical disadvantage in water access and repeated calls by Indigenous peoples and other for reallocation have so far been ignored (see for example the review of the Water Act 2007; Marshall 2017; Jackson 2017b). In my view, it is quite possible that any support that Indigenous peoples may have for the approaches of the past decade may well diminish if there is no material 
Author's copy: Jackson, S. 2018. Building trust and establishing legitimacy across scientific, water management and Indigenous cultures, Australasian Journal of Water Resources.

change to water distributions in coming years, and that this could further undermine the legitimacy of a water governance system that was imposed upon Indigenous peoples. It may be that such an outcome occurs even though there is strong interest evident in the research and water planning communities for closer collaboration, and some experimentation in processes and procedures, as the next section will show.

\section{Techniques and methods for building trust and legitimacy in environmental water management}

As a result of the procedural turn described above, research on participatory and collaborative approaches to water planning and management has been a growing topic of interest. This is evident in the literature that focuses specifically on collaboration involving Indigenous peoples (Hughey et al. 2017; Simms et al. 2016; von de Porten and Lou 2014; Maclean and Bana Yarralji Bubu Inc 2015; Ayre and MacKenzie 2013; Cranney and Tan 2011). Research on water planning in a number of regions of Australia has been designed to facilitate group processes in ways that promote exchange of understanding, encourage deliberation, build trust and deal with conflict between members and the government (see Tan et al. 2010; Straton et al. 2011; Jackson et al. 2012; Jackson et al. 2015; Ayre et al. 2018). This work contributes to the range of collaborative methods that government agencies, universities, research institutes, and NGOs employ to recognise and utilise Indigenous knowledges and deliver benefits to Indigenous experts and their communities (e.g. Hill et al. 2012; Louis 2007). Within this work, authors note that until recently there has been little interest from aquatic ecologists in Indigenous ecological knowledge (Crook et al. 2016) and it is seldom, if ever, used as a source of knowledge in the determination of environmental flow requirements (Finn and Jackson 2011; Cranney and Tan 2011). Building trust and establishing legitimacy in environmental water management will require that the research sector address this shortcoming as a matter of priority.

At the national scale, a project conducted by Tan et al. (2010) trialed a number of tools in participatory research with communities around Australia, including Indigenous communities, 
Author's copy: Jackson, S. 2018. Building trust and establishing legitimacy across scientific, water management and Indigenous cultures, Australasian Journal of Water Resources.

with a view to developing guidelines for water planning. Tan et al. defined community confidence in a water plan as

'... the extent to which the community trusts that government processes work, and that these processes will produce an outcome that is consistent with broadly held community values. Community confidence in a water plan is improved if it respects and reflects the community's broad values and norms, the decisions and implications of the plan are desirable or appropriate, it is technically credible, capable of being implemented, and has followed due process' $(2010,8)$.

The researchers documented the factors that contributed to participant confidence in the process, and these included:

- the independence and credibility of scientists and experts;

- participatory and inclusive methods of gathering information where information gaps are identified or perceived;

- methods that embrace complexity and are capable of providing a direct means of communicating community values to decision-makers; and

- evaluating and comparing the range of planning tools for good process and technical quality, so that it is clear why certain approaches have been used, and what their limitations are (Tan et al. 2010).

At the very least, building confidence, trust and credibility requires that researchers take the time to work within Indigenous governance structures, attempt to establish a two-way exchange of knowledge and a basis for reciprocity. Additionally it requires that researchers assist Indigenous communities to understand the water policy context, their rights and interests, and opportunities to influence decisions (see for example Jackson et al. 2015; Jackson and Altman 2014; Ayre et al. 2018). Such a need is based on the premise that there are asymmetries in power across differently positioned groups that affect access to information and capacity to participate in research projects, water planning and policy-making. Furthermore, that this context demands that extra effort be given to modes of communication across cultures (see Woodward et al. 2012; Crook et al. 2016). 
Author's copy: Jackson, S. 2018. Building trust and establishing legitimacy across scientific, water management and Indigenous cultures, Australasian Journal of Water Resources.

A number of these studies employed the principles of participatory action research (see for example Tan et al. 2010), where an iterative process of creating and applying jointly produced data breaks down barriers between researchers, government scientists and water planners and Indigenous community members. One successful study examined the similarities and differences in Indigenous ecological knowledge and scientific knowledge relating to the ecology of fish in the Daly River in the NT (Jackson et al. 2015). Researchers from the Tropical Rivers and Coastal Knowledge (TRaCK) consortium invited Jawoyn, Wagiman and Wardaman language groups to join as study partners in recognition of their twin roles as custodians with local knowledge of their customary estates and as statutory landowners who will continue to fulfil responsibilities for river health well into the future. After 13 years of shared field and other work, the research relationship that emerged from this partnership is one of the regions longest and most productive.

The original intention was to contribute to the determination of the environmental water requirements of fish, which are of significant cultural and economic value to indigenous communities in most parts of Australia. Previous e-flows research in this region had however overlooked Indigenous fish knowledge and used barramundi as the keystone fish when there are many other species of importance to Aboriginal groups (Finn and Jackson 2011). In addition to influencing the e-flow rules of the water allocation plan, there were many beneficial outcomes from this trusted partnership, including building the capacity of a number of Indigenous people to contribute to water planning and conservation management decisions (see Jackson et al. 2015). Like many efforts to reform research practices with Indigenous peoples, those involved in the project and the ones that have followed since focused heavily on procedural issues (DavidsonHunt and O'Flaherty 2007). The partners consider it a success because the researchers and Indigenous experts embarked on a process of continual dialogue and genuine negotiation that extended beyond mere adherence to procedures, such as human ethics approval (Crook et al. 2016).

\section{Agreements as frameworks for building trust and legitimacy}

This example brings me to a final point I would like to make about other enabling conditions and procedures to support trust and legitimacy in such contexts. Researchers and Indigenous 
Author's copy: Jackson, S. 2018. Building trust and establishing legitimacy across scientific, water management and Indigenous cultures, Australasian Journal of Water Resources.

communities are increasingly using research agreements as a framework for establishing mutually beneficial relationships, for guiding the ethical conduct of research, and for preventing or resolving tensions should disputes arise. The negotiation of settlements by Indigenous peoples and those with whom they are engaged in sharing land and water resources has long been an approach to the resolution of disputes over territory. Modern agreements and treaties provide an avenue for Indigenous and local people to address both historical disputes arising from the failure to reach a fair settlement or to honour colonial treaty promises and grievances arising from new developments (Tehan et al. 2006) not least those relating to contemporary water problems. According to Tehan et al. (2006, 2), agreements offer Indigenous peoples 'a way to negotiate their way into the nation state, particularly in areas concerning land access, social and environmental management, and associated infrastructure development'. The MOU signed between MLDRIN and the Murray-Darling Basin Commission represents another example. Although not a legally binding document, in that case, MLDRIN perceived the MOU as

'central to its relationship between the [Murray-Darling Basin] Ministerial Council and the Commission, because it could establish the fundamental protocols of that relationship. There was also the potential for the MOU to articulate clearly the roles and responsibilities of the Commission and MLDRIN in the ongoing environmental and cultural management of the Murray River' (Morgan et al. 2008, 152).

In order to negotiate such agreements potential collaborators need to spend time together building trust and discussing relevant terms, processes and outcomes for the collaboration or partnership (Ayre et al. 2018; Crook et al. 2016). In a research context, the TRaCK fish and flows partnership was established under an agreement that promoted the sharing of benefits, ensured protection of Indigenous intellectual property and adherence to Indigenous protocols. A review of the agreement within five years provided Indigenous oversight of the research activity. New research now being conducted under the National Environmental Science Program in the Kimberley has tied seven projects operating in the Fitzroy River catchment together under one umbrella research agreement between participating research organisations and the Kimberley Land Council. Projects have subagreements with the multiple Prescribed Body Corporates constituted under the Native Title Act 
Author's copy: Jackson, S. 2018. Building trust and establishing legitimacy across scientific, water management and Indigenous cultures, Australasian Journal of Water Resources.

1993 (Cth), depending on the location of their field study sites. In that program, two linked projects are seeking to determine environmental water requirements in the context of increasing demand for water from the agricultural sector. Indigenous peoples' knowledge, values, perspectives and governance arrangements are central to these and other projects working under the Northern Australian Environmental Resources Hub and for that reason researchers spent at least 12 months negotiating the terms of the research agreement and sub-agreements before commencing research.

Beyond the field of research, agreements have much to offer the conduct of environmental water management, particularly as a means of negotiating co-management arrangements. The Ngarrindjeri case from South Australia is illustrative. In the Coorong, Lower Lakes and Murray mouth region, traditional owners and the South Australian government have negotiated many of the components of an effective Indigenous engagement strategy and framework relating to environmental water management (Hemming and Rigney 2014). This work has been led by Ngarrindjeri leaders over the last two decades, a process in which the Ngarrindjeri Regional Authority (NRA) has played a key role in negotiating with the State water agency. The arrangements are now codified in a binding agreement - Kungun Ngarrindjeri Yunnan Agreement (Listen to Ngarrindjeri people talking); KNYA) entered into between Ngarrindjeri and various Ministers of the Crown in South Australia. Interactions between government and Ngarrindjeri take place through the Kungun Ngarrindjeri Yunnan Agreement Task Force, which occur monthly, and Leader-to-Leader meetings.

In 2015 the NRA and the CEWH signed an environmental water delivery partnership agreement which inter alia,

... establishes a framework for coordinating environmental watering undertaken by the $N R A$ and $C E W H$, including an agreed process for planning and managing the transfer, delivery and monitoring of Commonwealth environmental water in South Australia's wetlands, consistent with each party's obligations under the Basin Plan. 
Author's copy: Jackson, S. 2018. Building trust and establishing legitimacy across scientific, water management and Indigenous cultures, Australasian Journal of Water Resources.

The NRA approached the CEWH in order to ensure that wetlands and waterbodies within Ngarrindjeri estates would be cared for in accordance with Ngarrindjeri cultural protocols. The agreement allows for the NRA to submit watering proposals to the $\mathrm{CEWH}$, commits the parties to develop a process for NRA involvement in the management of Commonwealth environmental water and establishes an agreed communications protocol. As a clear example of a community exercising control of water governance (Hemming and Rigney 2014), these kinds of agreement hold much promise for environmental water management. As an expression of self-determination and recognition of the legitimacy of Indigenous modes of governance it is a marked improvement on the NWI and other exclusionary policy processes from which our current arrangements stem.

\section{Conclusion}

Ongoing conflict over the distribution and use of water affirms the need for greater legitimacy in the frameworks and procedures that allocate water and in the water programs that secure and manage water for the environment. The failure of Australian society and its institutions to provide sufficient recognition, respect, and autonomy for Indigenous laws, norms, aspirations, and wateruse practices also puts the spot light on legitimacy although from a different standpoint. Positioning legitimacy within post-colonial theory challenges the very fundamentals of our water governance system, as well as the presumptions of neutrality that underpin liberal water management principles of participation and inclusion. The procedural turn in water management has given rise to an explicit focus on political and ethical norms of trust and legitimacy. New procedures however are not designed in a neutral context (Schmidt 2014), rather they emerge from and are shaped by existing power relationships. In Australia's case, colonial relations of power cannot be assumed away as we seek to address over-use of water or redistribute it to the environment.

Strengthening the political and ethical norms of trust and legitimacy will therefore require that we reflect on and respond to the colonial relations of power that have structured Australian water governance and continue to cast a long shadow over water laws, policy, knowledge production and management practice. Efforts to build collaborative partnerships in research and in management are necessary but not sufficient conditions and may be forestalled if governments fail 
Author's copy: Jackson, S. 2018. Building trust and establishing legitimacy across scientific, water management and Indigenous cultures, Australasian Journal of Water Resources.

to acknowledge the claims of Indigenous peoples for a meaningful say in the governance of water, as well as its management. As a vehicle for bringing parties together, sharing knowledge, building understanding towards convergence of goals and enabling deliberation in the co-management of water (Collins and Ison 2010), agreement-making appears to be one from which trust and other positive outcomes can emerge, for example new norms of water use and decision criteria. Beyond the scale of local water planning and management, an agreement could serve as a framework for ensuring the inclusion of Indigenous people in the renegotiation of the NWI. Treaties are under discussion in a number of Australian states, presenting an opportunity to include water in their scope. By offering a structure for focusing on the procedural rules that allow meaningful deliberation to take place (Schmidt 2014), agreements offer parties at all levels of the water management sector - policy, administrative, research, management and practitioners - the opportunity to negotiate the rules governing legitimacy. 
Author's copy: Jackson, S. 2018. Building trust and establishing legitimacy across scientific, water management and Indigenous cultures, Australasian Journal of Water Resources.

\section{Acknowledgments}

I would like to acknowledge the support of the Australian Research Council's Future Fellowships Program funding scheme (project number FT130101145) and the National Environmental Science Program's Northern Australia Environmental Resources Hub. In addition, I acknowledge the many Indigenous communities with whom I have worked, and Michael Douglas of the University of Western Australia who has shared the collaborative journey taken via the north Australian projects referred to above. I am also grateful to the organisers of the ACSS workshop on trust and legitimacy in environmental water management: Erin O’Donnell, Avril Horne, Lee Godden and Brian Head.

I dedicate this article to the memory of Michael Storrs, a gentle and influential scientist who was instrumental in establishing a leading Indigenous land management program and had much to teach us about collaboration.

\section{Declaration of interest statement}

I have no conflicts of interest. 
Author's copy: Jackson, S. 2018. Building trust and establishing legitimacy across scientific, water management and Indigenous cultures, Australasian Journal of Water Resources.

\section{References}

Arnstein, S. 1969. A ladder of citizen participation, Journal of the American Institute of Planners. 35: $216-224$

Ayre, M., and J. Mackenzie. 2013. "Unwritten, unsaid, just known”: the role of Indigenous knowledge(s) in water planning in Australia. Local Environment 18: 753-768.

Ayre, M., P. Wallis, and K. Daniell. 2018. Learning from collaborative research on sustainably managing fresh water: implications for ethical research-practice engagement. Ecology and Society 23(1):6

Backstrand, K. 2006. Multi-stakeholder partnerships for sustainable development: Rethinking legitimacy, accountability and effectiveness. Eur. Env. 16, 290-306.

Borrows, J. 1997. Living between water and rocks: First Nations, environmental planning and democracy. University of Toronto Law Journal 47, 417-468.

Burchi, S. 2005. The interface between customary and statutory water rights - a statutory perspective, FAO Legal Papers Online, No. 45. Rome: FAO.

Collins, K., and R. Ison. 2010. Trusting emergence: Some experiences of learning about integrated catchment science with the environment agency of England and Wales. Water Resources Management 24: 669-688.

Cranney, K., and P. Tan. 2011. Old knowledge in freshwater: Why traditional ecological knowledge is essential for determining environmental flows in water plans. The Australasian Journal of Natural Resources Law and Policy 14: 71-113.

Crook, D., Douglas, M., King, A., and S. Schnierer 2016. Towards deeper collaboration: Stories of Indigenous interests, aspirations, partnerships and leadership in aquatic research and management. Reviews in Fish Biology and Fisheries 26: 611-615.

Davidson-Hunt, I., and M. O'Flaherty. 2007. Researchers, indigenous peoples, and place-based learning communities. Society \& Natural Resources: An International Journal 20: 291-305

Dryzek, J. 2001. Legitimacy and economy in deliberative democracy. Political Theory 29: 651669.

Dryzek, J. 2005. Deliberative democracy in divided societies: Alternatives to agonism and analgesia. Political Theory 33: 218-242.

Finn, M., and S. Jackson. 2011. Protecting indigenous values in water management: a challenge to conventional environmental flow assessments. Ecosystems 14(8): 1232-1248. 
Author's copy: Jackson, S. 2018. Building trust and establishing legitimacy across scientific, water management and Indigenous cultures, Australasian Journal of Water Resources.

Hartwig, L., Jackson, S., and N. Osborne. 2018. Recognition of Barkandji water rights in Australian settler-colonial water regimes. Resources 7(1): 16.

Hemming, S., and D. Rigney. 2014. Indigenous engagement in environmental water planning, research and management. Innovations in South Australia's Murray-Darling Basin Region, Goyder Institute for Water Research Technical Report Series No. 14/21, Adelaide, South Australia.

Hill, R., C., Grant, M., George, C. J. Robinson, S. Jackson and N. Abel 2012. A typology of Indigenous engagement in Australian environmental management: Implications for knowledge integration and social-ecological system sustainability, Ecology and Society 17 (1): 23. [online] URL: http://www.ecologyandsociety.org/vol17/iss 1/art23/.

Horangic, A., Berry, K., and T. Wall. 2016. Influences on stakeholder participation in water negotiations: a case study from the Klamath Basin. Society \& Natural Resources 29: 1421-1435.

Hughey, K., C. Jacobson, and E. Smith. 2017. A framework for comparing collaborative management of Australian and New Zealand water resources. Ecology and Society 22(4):28

Ivison, D. 2017. Pluralising political legitimacy. Postcolonial Studies 20: 118-130.

Jackson, S. 2006. Compartmentalising culture: the articulation and consideration of Indigenous values in water resource management. Australian Geographer 37: 19-32.

Jackson, S. 2017a. How much water does a culture need? Environmental water management's cultural challenge and Indigenous responses. In Water for the Environment, eds. Horne, A., Webb, A., Stewardson, M., Richter, B., and M. Acreman, 173-188. London: Elsevier.

Jackson, S. 2017b. Enduring injustices in Australian water governance. In Natural Resources and Environmental Justice: The Australian Experience, eds. Lukasiewicz, A., Dovers, S., Robin, L., McKay, J., Schilizzi, S., and S. Graham, 121-132. Melbourne: CSIRO Publishing.

Jackson, S., and J. Altman. 2009. Indigenous rights and water policy: perspectives from tropical northern Australia. Australian Indigenous Law Review 13(1): 27-48.

Jackson, S., Tan, P. and J. Altman 2009. Indigenous Fresh Water Planning Forum: Proceedings, Outcomes and Recommendations, Canberra: National Water Commission.

Jackson, S., Douglas, M. M., Pusey, B. J., Kennard, M. J., Huddleston, J., Harney, B., Liddy, L., Liddy, M., Liddy, R., Sullivan, E., Huddleston, B., Banderson, M., and Q. Allsop. 2014. 'We like to listen to stories about fish': Combining Indigenous and scientific fisheries knowledge to inform environmental flow assessment. Ecology and Society 19(1), 43. 
Author's copy: Jackson, S. 2018. Building trust and establishing legitimacy across scientific, water management and Indigenous cultures, Australasian Journal of Water Resources.

Jackson, S., and M. Douglas. 2015. Indigenous engagement in tropical river research in Australia: The TRaCK Program. The International Indigenous Policy Journal 6(2): Retrieved from: http://ir.lib.uwo.ca/iipj/vol6/iss2/3

Jackson, S., Tan, P., and S. Nolan. 2012. Tools to enhance public participation in the development of the Howard East aquifer water plan, Northern Territory. Journal of Hydrology 474: 22-28.

Maclean, K., and The Bana Yarralji Bubu Inc 2015. Crossing cultural boundaries: Integrating Indigenous water knowledge into water governance through co-research in the Queensland Wet Tropics, Australia. Geoforum 59: 142-152.

Marshall, V. 2017. Overturning aqua nullius. Canberra: Aboriginal Studies Press.

Morgan, M., Strelein, L., and J. Weir. 2006. Authority, Knowledge and Values: Indigenous Nations Engagement in the Management of Natural Resources in the Murray Darling Basin. In Settling with Indigenous People: Modern Treaty and Agreement-Making, ed M. Langton, M., 135156, Melbourne: Federation Press.

Mostert, E. 2003. The challenge of public participation. Water Policy 5: 179-197.

National Water Commission. 2014. Biennial Assessment Report, Canberra: National Water Commission.

Productivity Commission. 2017. National Water Reform Report No. 87. Canberra: Australian Government.

Schmidt, J. 2014. Water management and the procedural turn: Norms and transitions in Alberta. Water Resource Management 28: 1127-1141.

Simms, R., Harris, L. Joe, N., and K. Bakker. 2016. Navigating the tensions in collaborative watershed governance: Water governance and Indigenous communities in British Columbia, Canada. Geoforum 73: 3-16.

Straton, A., Jackson, S., Marinoni, O., Proctor, W., and E. Woodward. 2011. Exploring and evaluating scenarios for a river catchment in northern Australia: using combined scenario development, multi-criteria analysis and a deliberative process as a tool for water planning. Water Resources Management 25: 141-149.

Tan, P., Mooney, C., White, I., Hoverman, S., Mackenzie, J., Burry, K., Baldwin, C., Bowmer, K., Jackson, S., Ayre, M., and George, D. 2010. Tools for water planning: lessons, gaps and adoption, Waterlines Report, Canberra: National Water Commission. 
Author's copy: Jackson, S. 2018. Building trust and establishing legitimacy across scientific, water management and Indigenous cultures, Australasian Journal of Water Resources.

Taylor, K. Moggridge, M., and A. Poelina. 2017. Australian Indigenous Water Policy and the impacts of the ever-changing political cycle. Australasian Journal of Water Resources 20: 132147.

Tan, P., Bowmer, K, and J. McKenzie. 2012. Deliberative tools for meeting the challenges of water planning in Australia. Journal of Hydrology 474: 2-10

Tan, P., Bowmer, K., and C. Baldwin. 2012. Continued challenges in the policy and legal framework for collaborative water planning. Journal of Hydrology 474: 84-91.

Tehan, M., Palmer, L., Langton, M. and O. Mazel 2006. Sharing land and resources: Modern agreements and treaties with indigenous people in settler states. In Settling with Indigenous People: Modern Treaty and Agreement-Making, ed M. Langton, 1-18. Melbourne: Federation Press.

Tully, J. 2000. The struggles of Indigenous peoples for and of freedom, in Political Theory and the Rights of Indigenous Peoples. Cambridge University Press, Cambridge.

Turner, D., 2006. This is not a peace pipe: Towards a critical indigenous philosophy. University of Toronto Press, Toronto.

Von der Porten, S., and R. de Loe. 2013. Collaborative approaches to governance for water and Indigenous peoples: A case study from British Columbia, Canada. Geoforum 50: 149-160.

Watson, I. 2009. Sovereign Spaces, Caring for Country, and the Homeless Position of Aboriginal Peoples. South Atlantic Quarterly 108: 27-51.

Weir, J., and S. Ross, 2007. Beyond native title: Murray Lower Darling Rivers Indigenous Nations. In The social effects of native title: Recognition, translation, coexistence, eds B. Smith and F. Morphy, 185-201, Canberra: AIATSIS.

Wolfe, P. 2006. Settler colonialism and the elimination of the native. Journal of Genocide Research 8: 387-409.

Woodward, E., Jackson, S., Finn, M., and P. Marfurra McTaggart. 2012. Utilising Indigenous seasonal knowledge to understand aquatic resource use and inform water resource management in northern Australia. Ecological Management and Restoration 13(1): 58-64. 